\title{
Parallel loop binding compression suture, a modified procedure for pernicious placenta previa complicated with placenta increta: a retrospective study. (with video)
}

\author{
Mengdi $\mathrm{Fu}^{1}$, Hualei Bu${ }^{1}$, Yan Fang ${ }^{1}$, Chunling Wang ${ }^{2}$, Li Zhang ${ }^{2}$, Yang Zhang ${ }^{2}$, Xiao Sun ${ }^{2}$, \\ Mingbao $\mathrm{Li}^{1}$, Chengjuan $\mathrm{Jin}^{3}$, Yintao $\mathrm{Xu}^{2}$, and Lijun $\mathrm{Chen}^{2}$ \\ ${ }^{1}$ Shandong University Qilu Hospital \\ ${ }^{2}$ Affiliation not available \\ ${ }^{3}$ Shanghai General Hospital
}

August 10, 2021

\begin{abstract}
Abstract Objective. To evaluate the efficacy and safety of parallel loop binding suture of the lower uterus during cesarean section in pernicious placenta previa complicated with placenta increta. Design. A retrospective study Setting. Qilu Hospital of Shandong University Population. Patients with pernicious placenta previa between November 2014 and December 2020 at the Qilu Hospital of Shandong University were eligible. Methods. The degree of placental invasion was evaluated using preoperative color Doppler ultrasonography and/or magnetic resonance imaging (MRI). Main outcome measures. Postpartum hemorrhage was evaluated as the primary outcome. Additionally, neonatal outcomes were evaluated. Results. Of the 38 patients, only $3(7.89 \%)$ underwent hysterectomy due to massive blood loss. With parallel loop binding compression suture, the volume of blood lost ranged from 500 - 6000 (mean: 2152.63土1169.37) $\mathrm{mL}$ and the volume of blood transfused was between $400-3200$ $(1431.58 \pm 699.85) \mathrm{mL}$. The mean gestational age was 36 weeks and 2 days (range: $32+6$ to39+6 weeks). The average operation time was $109.78 \pm 33.49 \mathrm{~min}$, and the average fetal childbirth time was $14.05 \pm 5.60 \mathrm{~min}$. The rate of NICU admission was $36.84 \%$ (14/38). The postoperative menstrual cycle and menstrual flow both returned to normal levels. All infants at our hospital were safely discharged after treatment. Conclusion. Parallel loop binding compression suture is an effective, swift, practical, and safe method to reduce postpartum bleeding in women with pernicious placenta previa, complicated with placenta increta.
\end{abstract}

\section{Hosted file}

Manuscript 0730.docx available at https://authorea.com/users/430067/articles/533619-parallelloop-binding-compression-suture-a-modified-procedure-for-pernicious-placenta-previacomplicated-with-placenta-increta-a-retrospective-study-with-video 

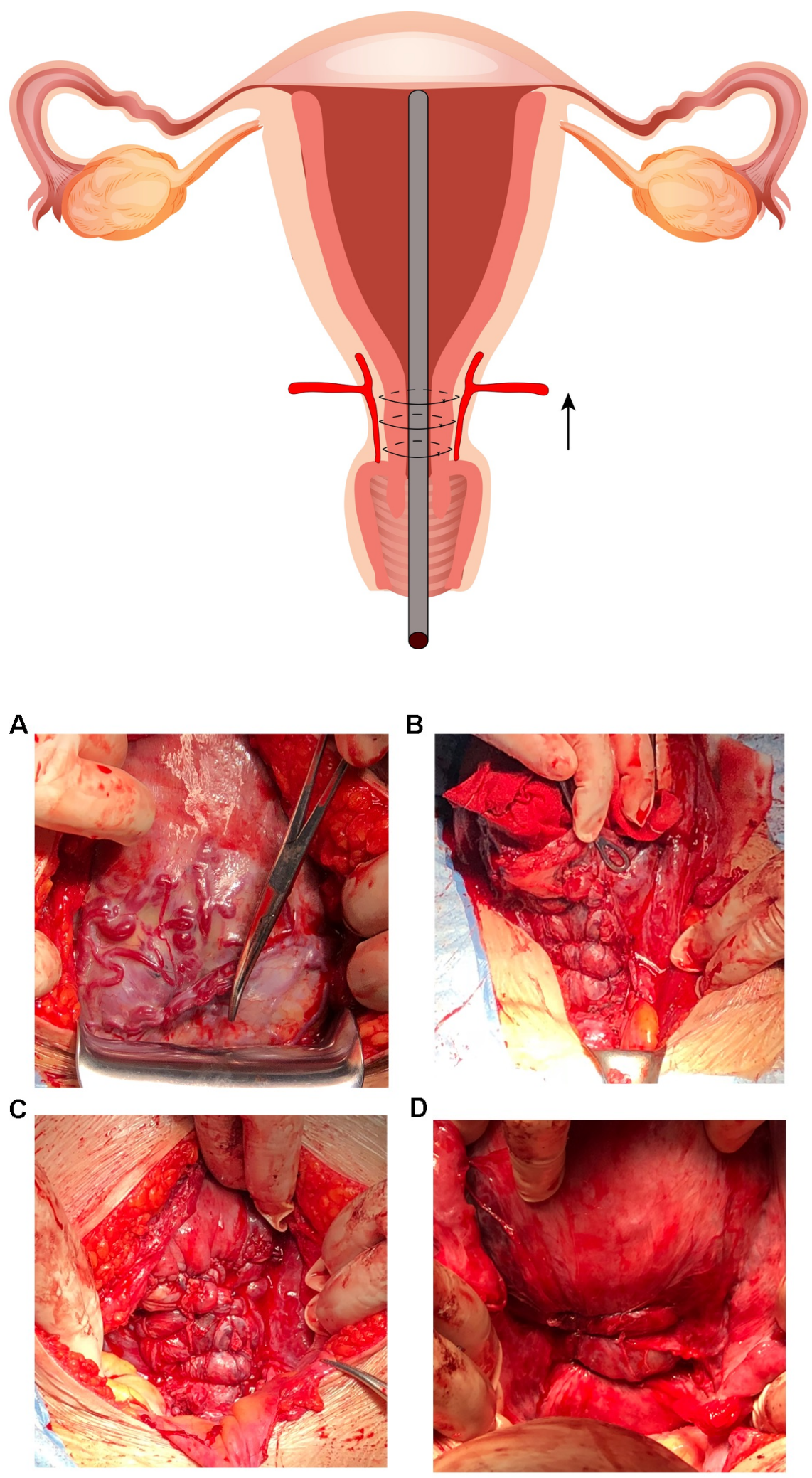